\title{
LA EMIGRACIÓN ESPAÑOLA A AMERICA LATINA DURANTE EL PRIMER FRANQUISMO (1939-1959) Interrupción y reanudación de una corriente tradicional
}

Salvador Palazón Ferrando Universidad de Alicante

La voluminosa emigración española que abarrotó los buques que se dirigían a los puertos latinoamericanos durante el período 1880 a 1930 , se verá prácticamente paralizada desde mediados de los años treinta hasta finales de los cuarenta, cuando se restablece el flujo migratorio con rumbo a América Latina. Es por ello que en el período abarcado por el primer franquismo (1939-1959) se pueden establecer dos etapas: la primera, entre los años 1939 y 1946, en la que asistimos a una continuación de la interrupción sufrida por la corriente con posterioridad a 1935; y, la segunda, desde 1946 a 1958, cuando se produce una reanudación de la emigración exterior española con rumbo a Latinoamérica (véase Cuadro I).

\section{1939-1945: UNA INTERRUPCION CONTINUADA}

La casi total paralización sufrida por la emigración exterior española con destino a América Latina que tiene lugar a partir de 1935, como consecuencia de la guerra civil española y del endurecimiento de las políticas inmigratorias de los países latinoamericanos, resultado a su vez de la grave crisis económica que padecen debido a los efectos de la Gran Depresión de 1929, se ve continuada durante los primeros años de la década de los cuarenta.

Tres son los motivos que contribuyen a mantener interrumpida la corriente migratoria española con América Latina: $1^{\circ}$ ) las restricciones impuestas por el nuevo régimen político en España; $2^{\circ}$ ) la Segunda Guerra Mundial; y $3^{\circ}$ ) la continuación de unas políticas inmigratorias selectivas en unos países latinoamericanos poco dispuestos a recibir una inmigración masiva de las características de la llegada con anterioridad a 1930. De ahí que la emigración directa desde España se vea superada por los contingentes de refugiados españoles que desde países próximos, sobre todo desde Francia, se dirigen a América. Así, entre 1939 y 1945, mientras los emigrantes españoles a América suman poco más de 21.000 efectivos $^{1}$, los refugiados españoles

\footnotetext{
${ }^{1}$ De los cuáles debemos pensar que muchos de ellos tenían carácter de refugiados encubiertos, pues eran reclamados por sus parientes o amigos en América para evitarles los posibles padecimientos innecesarios que la postguerra les deparaba.
} 
llegados a América Latina desde el otro lado del Atlántico superan los 24.000, si bien los destinos se concretaron en cuatro países: México, a donde llegan 16.103, la República Dominicana, que recibe más de 3.000, Ecuador, que acoge 2.458 y Chile, a donde arriban $2.200^{2}$; el resto de países apenas recibió directamente refugiados ante el temor de que pudieran propagar ideas extremistas, y únicamente llegaron a ellos fruto de la reemigración procedente de alguno de sus países vecinos que sí les permitieron la entrada.

CUADRO I

Movimiento migratorio español a América latina, 1882-1935

\begin{tabular}{|c|r|r|r|r||}
\hline PERIODO & EMIGRACION & RETORNO & SALDO & $\begin{array}{c}\text { EMIGRACION } \\
\text { MEDIA } \\
\text { ANUAL }\end{array}$ \\
\hline $1882-1900$ & 926.290 & 594.931 & -331.359 & 48.752 \\
$1901-1910$ & 823.844 & 356.180 & -467.664 & 82.384 \\
$1911-1920$ & 1.011 .739 & 671.650 & -340.089 & 101.174 \\
$1921-1930$ & 7099.882 & 491.735 & -218.147 & 70.988 \\
$1931-1935$ & 104.916 & 179.662 & 74.746 & 20.983 \\
$1936-1939$ & 14.440 & 13.667 & -773 & 3.610 \\
$1940-1945$ & 20.116 & 10.617 & -9.499 & 3.353 \\
$1946-1950$ & 131.814 & 23.947 & -107.867 & 26.363 \\
$1951-1958$ & 428.401 & 138.350 & -290.051 & 53.550 \\
\hline
\end{tabular}

FUENTE: INSTITUTO GEOGRÁFICO Y ESTADÍSTICO: Estadística de la emigración e inmigración de España 1882-1911; Estadística de pasajeros por mar, 1912-1918; DIRECCION GENERAL DE ESTADISTICA: Estadística de pasajeros por mar, 1919; MINISTERIO DE TRABAJO, INDUSTRIA Y COMERCIO: Estadística de pasajeros por mar, 1920-1922; SERVICIO GENERAL DE ESTADISTICA: Estadística del movimiento de buques y pasajeros por mar con el exterior, 1923. 1925; INSTITUTO GEOGRAFICO, CATASTRAL Y ESTADISTICO: Estadística del movimiento de buques y pasajeros por mar con el exterior, 1926-1935; INSTITUTO ESPANOL DE EMIGRACION, Memoria anual, 1987, 1936-1945; DIRECCION GENERAL DE TRABAJO: Estadísticas de Emigración,(E.E.), 1946-1951; Estadísticas del Movimiento Migratorio Transoceánico, (E.M.M.T.), 1952-1956; Estadísticas de Repatriación Bonificada, (E.R.B.), 1951-1956; Estadísticas de Migración y Repatriación Bonificada, (E.M.R.B.), 1957; Estadisticas de Emigración, Retorno y Repatriación Bonificada, (E.E.R.R.B.), 1958. Elaboración propia.

\subsection{Las restricciones del nuevo régimen político en España}

Las cortapisas impuestas a la salida de españoles por el régimen franquista en sus primeros años fueron una de las causas que trabaron el flujo emigratorio hacia el exterior. Así, tras la finalización de la guerra civil, el régimen franquista restringió ${ }^{3}$

${ }^{2}$ Estos 24.000 refugiados no están incluidos en el Cuadro I porque no salen directamente desde España, para su contabilización se ha recurrido a los datos facilitados por RUBIO, J., La emigración de la guerra civil. 1936-1939, Madrid, Ed. San Martin, 1977, LLORENS, V., "La emigración republicana de 1939", en Abellán, J.L., El exilio español de 1939. Tomo I, Madrid, Taurus, 1976 y BELISLE, J.F., "Los inmigrantes y la economía ecuatoriana en la primera mitad del siglo XX", en $46^{2}$ Congreso Internacional de Americanistas, Amsterdam, 1988, inédito.

${ }^{3}$ Utilizamos la palabra restringir y no prohibir porque la emigración española, aunque muchos autores así lo indiquen, no estuvo prohibida de derecho durante los primeros años del franquismo. Dos normas así lo corroboran: la primera es el Decreto de 6 de abril de 1943 por el cual se exige a los jóvenes que quieran emigrar la constitución de un depósito en metálico en la Intendencia General Militar, que iba 
las salidas de españoles al extranjero mediante la concesión de pasaportes con verdadero "cuentagotas" ${ }^{\prime 4}$, en un intento por: $1^{\circ}$ ) evitar la huída del país de aquellos considerados como colaboradores del régimen republicano y que debían ser juzgados; $2^{\circ}$ ) impedir la salida de las escasas divisas que había en el país; y $3^{\circ}$ ) alcanzar el principal objetivo de la política demográfica franquista: los 40 millones de habitantes .

\subsection{La Segunda Guerra Mundial}

Al igual que ocurrió durante la Primera Guerra Mundial, uno de los efectos inmediatos del conflicto fue la utilización de gran parte de los barcos dedicados hasta entonces al transporte de pasajeros, para el transporte de tropas, heridos, alimentos, material de guerra, etc., con lo cual las posibilidades de cruzar el Atlántico quedaban mermadas por falta de buques. Además, la extensión de la guerra submarina a ambos hemisferios puso en peligro las travesías marítimas aunque estas tuviesen como procedencia y destino países no beligerantes.

\subsection{La selectiva política inmigratoria de los países latinoamericanos}

Si antes de 1936 gran parte de los países de América Latina ya habían iniciado una política inmigratoria restrictiva, el empeoramiento de las condiciones socio-económicas y el convencimiento de que sólo la explotación de sus inmensas riquezas naturales y la estimulación de sus posibilidades industriales eran las soluciones para alcanzar niveles de vida superiores, obligaron a los países latinoamericanos a seguir las directrices marcadas por la Conferencia de Estados Americanos Miembros de la O.I.T., celebrada en 1936 en Santiago de Chile, según las cuales había que favorecer la inmigración pero sobre la línea de la más pura conveniencia nacional ${ }^{6}$.

En general, todos los países latinoamericanos se pronuncian entre 1936 y 1945 por la adopción de nuevas medidas encaminadas a la restricción y selección de la inmigración, así como a la protección de la población autóctona; en la mayor parte de las ocasiones, rehuyen admitir a individuos con ideologías "extremistas",

\footnotetext{
desde 150 pesetas para los jóvenes con 16 años hasta 300 para los que tenían 20 años (es evidente que si la emigración hubiese estado prohibida de derecho nunca se hubiera promulgado tal decreto); y la segunda norma es la Orden de 29 de marzo de 1946, que muchos autores indican como la que restablece las posibilidades de emigrar, pero que en realidad no se limita más que a recordar que en materia migratoria sigue estando vigente el Real Decreto de 20 de diciembre de 1924.

${ }^{4}$ PUYOL ANTOLIN, R., Emigración y desigualdades regionales en España, Madrid, EMESA, 1979, p. 45.

${ }^{5}$ NAVARRO LOPEZ, M., "El contexto socio-económico de la emigración continental española (19451975)", en GARMENDIA, J.A., La emigración española en la encrucijada. Marco general de la emigración de retorno, Madrid, CIS, 1981, pp. 20-21.

${ }^{6}$ MARTI BUFILL, C., Nuevas soluciones al problema migratorio, Madrid, Ed. Cultura Hispánica, 1955, p. 43.
} 
contrarias a los intereses o a la estabilidad del Estado ${ }^{7}$, incluyendo a los refugiados de guerra.

\subsection{Consecuencias geodemográficas de la interrupción emigratoria}

La caída experimentada por los volúmenes emigratorios españoles desde 1930 , así como la mortalidad por envejecimiento de los españoles llegados en la segunda mitad del siglo XIX, tuvieron como consecuencia directa el descenso de la población española que se había asentado en América Latina con anterioridad a 1936. Esta afirmación queda sustentada con los datos que sobre residentes españoles nos ofrecen los censos de población realizados en los países que habían sido los principales destinos del movimiento emigratorio español hasta la década de 1930 , y su comparación con los últimos realizados en el período anterior ${ }^{8}$.

En Argentina donde estaba radicada la principal colonia española de Latinoamérica, la población española censada en 1947 se reduce en un 11\% con respecto a la existente en 1914 (los 841.149 españoles censados entonces pasado a ser 749.392), pero, aún así, mantiene su primacía, pues la cifra de españoles residentes en ella cuadruplica a la de asentados en Cuba o Brasil.

En Cuba, el descenso de los españoles censados en 1943 (157.527) sobre los presentes en 1930 (257.596), es el mayor - un 39\% - de todos los experimentados en América Latina, y supone que la colonia asentada en esta isla, que antes de 1935 era la segunda en importancia numérica de todo el área, quede relegada a un tercer lugar, tras Argentina y Brasil.

En Brasil, si bien la población española contabilizada en 1940 conoció un importante decremento (27\%) con respecto a la existente en 1920 (219.142), el resultado supondría que los 160.557 españoles residentes en este país superen numéricamente a los afincados en Cuba, y que la colonia española de Brasil pase a ser la segunda en importancia numérica de América Latina, tras Argentina.

México fue el único país de este grupo que aumentó la presencia española en sus tierras como consecuencia de la recepción de refugiados españoles; de hecho, la colonia española presente en México en 1930 (28.855) se había incrementado ligeramente (2\%) diez años más tarde (los españoles ascienden ahora a 29.544).

En Chile, la llegada de refugiados españoles permitió que la colonia española de 1930 (cifrada en 23.439 españoles) se mantuviese prácticamente en los mismos valores en el recuento oficial de 1940 (23.439).

\footnotetext{
${ }^{7}$ Para más detalle véase PALAZÓN FERRANDO, S.: "La política inmigratoria en los países de América del Sur: del estímulo a la restricción (1850-1980)", en Eiras Roel, A. (Coord.), Emigración española y portuguesa a América, Alicante, Instituto de Cultura Juan Gil-Albert-Semirari d'Estudis sobre la Població del País Valencià, pp. 127-136.

8 El único de estos países sobre el que no se ofrece información es Uruguay, pues tras el censo de 1908 no realizará ningún otro hasta 1963.
} 


\section{1946-1958: REANUDACION DE UNA CORRIENTE MIGRA- TORIA TRADICIONAL}

\subsection{España: la emigración exterior como solución}

Durante el primer quinquenio de los años cuarenta, como hemos visto, la emigración exterior española se había encontrado con dificultades, sobre todo por las limitaciones a la emigración impuestas por parte del régimen político recién instaurado. En contraposición, durante la etapa entre 1946 y 1958 la situación cambiará casi radicalmente, puesto que el gobierno franquista pronto comprendió que la emigración española a Latinoamérica no representaba ningún peligro desde el punto de vista de las "infiltraciones ideológicas" sino que, por el contrario, permitía alimentar los sueños del Imperio y desembarazar al país de descontentos e inadaptados. Además, había hecho aparición la creencia oficial de que el país padecía una presión demografica ${ }^{10}$.

El resultado fue una política migratoria aperturista, que, beneficiándose de la consolidación del régimen franquista en el ámbito internacional, se plasmó en diversas medidas destinadas a facilitar la emigración. Entre estas medidas destacan: a) las facilidades para obtener el pasaporte, pues la Dirección General de Seguridad sólo exigirá, a partir de 1948, como requisito la presentación de una "carta de llamada" o de un contrato de trabajo visado por un consulado español; b) la Orden de 5 de enero de 1948 que permitirá la libre salida de divisas del país, al haber alcanzado el comercio exterior español cierta normalidad y existir una mayor disponibilidad de moneda extranjera; c) la firma de diversos convenios bilaterales con países latinoamericanos en los que se hará mención expresa al problema de la emigración; d) la creación del Instituto Español de Emigración (I.E.E.), en 1956, como instrumento destinado a planificar y controlar la emigración española, así como a asistir, orientar y facilitar un transporte más barato y la documentación necesaria a los emigrantes; y e) la adhesión, ese mismo año, al Comité Intergubernamental de Migraciones Europeas (C.I.M.E.), que permitía asegurar el transporte a los emigrantes con medios insuficientes desde España a Ultramar, e incrementar la emigración exterior española al asegurar la acogida, colocación inicial e instalación de los emigrantes de acuerdo a las peticiones de los Gobiernos interesados ${ }^{11}$.

Sin embargo, esta predisposición del Gobierno español a facilitar la emigración no es más que un reflejo de una situación económica interna incapaz de absorber la mano de obra excedentaria que generaban las áreas rurales, donde el aumento de la mecanización agrícola, el atractivo de salarios más elevados en la industria y el fracaso de la política colonizadora habían aumentado los desequilibrios campo-ciu-

\footnotetext{
${ }^{9}$ SAGRERA, M.: España Peregrina. La influencia de las migraciones actuales en la transformación sociocultural de España. México, Costa-Amic, 1970, p. 23.

${ }^{10}$ GARCÍA FERNÁNDEZ, J.: La emigración exterior de España, Barcelona, Ariel, 1965, pp. 20-22.

11 Entre los países latinoamericanos que componen el C.I.M.E. se encuentran: Argentina, Brasil, Colombia, Costa Rica, Chile, Paraguay, Uruguay y Venezuela.
} 
dad y el éxodo rural ${ }^{12}$. Este problema adquiere mayor relevancia si tenemos en cuenta que casi la mitad de la población activa española seguía ligada al sector agrario, y eso no hacía más que agudizar los problemas en un sector incapaz de alcanzar la plena ocupación y con importancia decreciente en las esferas económicas del país. Además, las regiones industrializadas con capacidad para absorber la fuerza de trabajo excedentaria en el campo continuaban siendo -en estos años- prácticamente las mismas de principios de siglo (Cataluña, País Vasco, Madrid), lo que limitaba las posibilidades de transferencia demografica desde el campo hacia el ámbito urbano.

Esta afirmación queda corroborada si tenemos en cuenta que de las nueve regiones con saldos migratorios netos negativos en la década de 1951-1960, (Andalucía, Aragón, Canarias, Castilla-La Mancha, Castilla-León -incluidas Cantabria y La Rioja-, Extremadura, Galicia, Murcia y País Valenciano), para las que disponemos de datos sobre la composición de su P.I.B. y de su población activa en 1955, todas presentan la mitad o más de su población activa dedicada al sector primario, e, incluso en seis de ellas la proporción del P.I.B. procedente del sector agrario supera la cuarta parte del total ${ }^{13}$. Por contra, en las tres regiones con saldos migratorios muy positivos -Cataluña, Madrid y País Vasco (incluida Navarra)-, el sector primario apenas tiene importancia ni como aportación al P.I.B. regional ni en la distribución de la población activa.

Ahora bien, no sólo las causas de tipo económico explican la emigración exterior española, en esta etapa podemos destacar también dos causas de orden social: la cadena migratoria resultante de la importante colonia española asentada en América Latina (hacia 1950 los españoles residentes en este área superan el millón), y el exilio al que se sometían los disidentes políticos con el régimen dictatorial del General Franco.

\subsubsection{Areas de origen de la emigración española transoceánica}

Como ya ocurría con anterioridad a 1930, se observa una desigualdad regional en el origen de los contingentes emigratorios con destino a América. Así, Galicia se

12 Tras la guerra civil se había producido una "vuelta" al campo de la mano de obra con el fin de reforzar la producción de alimentos, pero una vez logrado el autoabastecimiento, la exportación de fuerza de trabajo agraria hacia las actividades urbanas fue creciente a partir de 1951, como consecuencia del aumento de la mecanización agrícola y del atractivo de las ciudades, basado, sobre todo, en los salarios más elevados y seguros que ofrecía la industria (LEAL, J.L y OTROS: La agricultura en el desarrollo capitalista español (1940-1970). Madrid, Siglo XXI, 1977, pp. 223-224). Por otra parte, la Ley de Colonización de Grandes Zonas fue un absoluto fracaso, ya que del más de medio millón de hectáreas declaradas de interés nacional para ejecutar el plan sólo se transformaron una diez mil; por otra parte, el número de colonos nunca superó el $2 \%$ de los campesinos sin tierra y los lotes que recibían eran tan pequeños que pronto se revelaron antieconómicos(JULIÁ, S.: Historia económica y social moderna y contemporánea de España. Tomo II, Madrid, UNED, 1988, p. 148).

${ }^{13} \mathrm{Sin}$ olvidar que en algunas de estas regiones todavía se dan hechos que empeoran el panorama, como son el minifundismo antieconómico de Galicia, Asturias, Cantabria y La Rioja, el latifundismo andaluz, o la extensión del arrendamiento a corto plazo en ambas Castillas como sistema de explotación. 
constituye en este período en la región que más efectivos aporta a esta corriente migratoria exterior, superando los 250.000 emigrantes, de tal forma que casi la mitad de los emigrantes transoceánicos son de origen gallego. Canarias y Cataluña también superan cada una de ellas la cifra de 50.000 emigrantes, y si les sumamos los procedentes de Galicia, tenemos que estas tres regiones aportan más de las dos terceras partes del flujo emigratorio de este período.

Andalucía, Asturias, Madrid y Castilla-León, aportan cada una volúmenes entre los 25.000 y los 35.000 emigrantes, que unidos a los procedentes de las tres regiones anteriores, supone que de estas siete regiones sale casi el $90 \%$ de la emigración transoceánica total. Con cifras inferiores a los 20.000 emigrantes aparecen las restantes regiones, de las que cinco de ellas (Navarra, La Rioja, Murcia, Castilla-La Mancha y Extremadura) ni tan siquiera superan los 5.000 emigrantes transoceánicos (Cuadro II).

\section{CUADRO II}

\section{Origen regional de la emigración transoceánica española (1946-1958)}

\begin{tabular}{|c|c|c|c|}
\hline REGION & EMIGRANTES & $\%$ & TASA $^{14}$ \\
\hline $\begin{array}{l}\text { Andalucía } \\
\text { Aragón } \\
\text { Asturias } \\
\text { Baleares } \\
\text { Canarias } \\
\text { Cantabria } \\
\text { Castilla-La Mancha } \\
\text { Castilla-León } \\
\text { Cataluña } \\
\text { Extremadura } \\
\text { Galicia } \\
\text { Madrid } \\
\text { Murcia } \\
\text { Navarra } \\
\text { País Vasco } \\
\text { Rioja } \\
\text { Valencia }\end{array}$ & $\begin{array}{r}33.219 \\
5.021 \\
30.562 \\
6.614 \\
69.514 \\
6.508 \\
2.177 \\
25.011 \\
52.596 \\
1.397 \\
258.765 \\
27.406 \\
2.484 \\
4.331 \\
18.771 \\
3.597 \\
16.557\end{array}$ & $\begin{array}{r}5,88 \\
0,89 \\
5,41 \\
1,17 \\
12,31 \\
1,15 \\
0,39 \\
4,43 \\
9,32 \\
0,25 \\
45,84 \\
4,85 \\
0,44 \\
0,77 \\
3,33 \\
0,64 \\
2,93\end{array}$ & $\begin{array}{r}5 \\
4 \\
26 \\
12 \\
73 \\
12 \\
1 \\
5 \\
13 \\
1 \\
76 \\
11 \\
3 \\
9 \\
14 \\
12 \\
6\end{array}$ \\
\hline
\end{tabular}

FUENTE: E E. 1946-1951; E.M.M.T., 1952-1956; E.R.B., 1951-1956; E.M.R.B., 1957; E.ER R.B., 1958.

Censo de Población de España de 1950. Elaboración propia.

Asimismo a diferencia del período anterior a la guerra civil, la media anual de emigrantes transoceánicos españoles es mucho más baja (veáse Cuadro I). Tres pueden ser las causas, con incidencia variada según las regiones españolas, que motivaron este descenso:

1) El desarrollo industrial y urbano de Cataluña, Madrid y el País Vasco, lo que determinó una demanda de mano de obra que en gran parte fue suministrada por las regiones que presentan saldos migratorios negativos en la década de los cincuenta; de hecho, si en la década de 1921-30 Cataluña, Madrid y el País Vasco absorbieron una inmigración neta de 567.504 personas, es decir, un 2,66\% de la población

\footnotetext{
${ }^{14}$ Tasa media anual de emigrantes transoceánicos por cada diez mil habitantes censados en la región en 1950.
} 
censada en España en 1920, en la década de 1951-60, el saldo migratorio neto aumenta a 1.003.705 personas, o sea, un 3,59\% de la población censada en el país en 1950.

2) La política migratoria selectiva de los países latinoamericanos que, tal y como veremos, demandaba personal especializado (obreros industriales, técnicos y colonos agrícolas) para afianzar sus procesos de desarrollo económico; obviamente esta demanda chocaba con la realidad española, ya que, por un lado, los obreros industriales y el personal técnico no eran los más apropiados para constituir una corriente emigratoria masiva, ni abundaban en los años cuarenta y cincuenta en España, y, por otro, los campesinos no querían emigrar para seguir trabajando en el campo, incluso, en muchas ocasiones, no se les permitía permanecer en los núcleos urbanos, donde tampoco encontraban ahora las oportunidades de principios de siglo ${ }^{15}$.

3) Las necesidades de fuerza de trabajo inmigrante que presentaban los países de la Europa Occidental para llevar a cabo su proceso de reconstrucción, sobre todo a partir del año 1955; en este caso, los principales atractivos que estos países ofrecían al emigrante español con respecto a América eran tres: su cercanía, el menor coste de desplazamiento y la posibilidad de obtener salarios elevados en actividades de tipo urbano $^{16}$.

De todas las regiones españolas, en este período sólo dos presentan tasas elevadas de emigracion: Galicia y Canarias, con índices medios anuales en torno a los 75 emigrantes transoceánicos por cada diez mil habitantes de sus respectivos censos de 1950. En ambos casos se da una estructura económica incapaz de emplear a todos sus excedentes demográficos. Además en el caso gallego existe un importante volumen de compatriotas asentados ya en América que permite una gran cadena migratoria; mientras que para los canarios, Venezuela aparece ahora como un nuevo destino, tan atractivo como lo fuera en su momento Cuba.

Con tasas moderadas únicamente aparece una región, Asturias, cuyo comportamiento emigratorio exterior no coincide con el saldo inmigratorio que presenta en la década de 1951-60. Dado que este saldo viene derivado de la llegada de aportes extraprovinciales para la siderurgia y la minería, actividades que experimentan un gran auge en este período, y que estas actividades no eran las preferidas por la población rural autóctona, se entiende que el éxodo rural se dirigiese en gran parte a América, donde la existencia de una importante colonia asturiana asentada allí con anterioridad a la guerra civil permitiría que entrase en funcionamiento la cadena migratoria, tal y como ocurre en el caso gallego. El resto de regiones presentan tasas bajas o muy bajas, lo que en el caso de aquéllas que tienen saldos migratorios muy negativos en la década de los cincuenta nos indica una preferencia de sus emigrantes por destinos nacionales o europeos.

\footnotetext{
15 PUYOL, op. cit, p. 49.

${ }^{16}$ Por ejemplo, a Francia, según cifras del ONI, emigraron entre 1946 y 1958 un total de 102.801 españoles, y de ellos más de la mitad (57\%) lo hizo en los tres últimos años (1956- 1958)(RUBIO, J., La emigración española a Francia, Barcelona, Ariel, 1974, pp. 289 y 296).
} 


\subsection{América latina: expansión económica y demanda de inmigración cualificada}

El nuevo período de expansión económica que experimentan, a partir de 1946, los principales países latinoamericanos, fue debido, en unos casos, al auge de las exportaciones agropecuarias hacia los países europeos devastados por la Segunda Guerra Mundial o para el abastecimiento de las tropas estadounidenses durante la guerra de Corea (caso de Argentina y Uruguay), y, en otros, a los buenos precios internacionales de sus productos de exportación (como ocurre en Venezuela, Brasil, México o Colombia); todo ello derivó en un proceso de rápida industrialización. La falta de personal especializado para llevarlo a cabo, así como la necesidad de campesinos y sus familias para colonizar las extensas áreas todavía despobladas e improductivas o aquéllas que se habían visto afectadas por un intenso éxodo rural hacia las ciudades, determinó que desde América Latina surgiera una demanda de inmigrantes europeos con los siguientes perfiles: a) obreros industriales; b) técnicos para la industria y la ejecución de las obras de infraestructura necesarias para afianzar el progreso económico; c) colonos agrícolas y sus familias; y d) familiares directos (cónyuge e hijos) que mediante la reagrupación familiar permitiesen la permenencia y definitiva radicación en Latinoamérica de los inmigrantes llegados con anterioridad.

En realidad, el proceso selectivo de la inmigración extranjera había comenzado durante la década de los treinta ${ }^{17}$, pero es ahora cuando se generaliza, no sólo porque la demanda de un determinado tipo de inmigrantes es un hecho, sino también, porque los países latinoamericanos no estaban dispuestos a abrir sus puertas a los miles de europeos deseosos de abandonar sus asolados países hasta que éstos presentasen claros síntomas de recuperación económica.

En esta etapa (1946-1958) de reapertura de América Latina emigraron más de medio millón de españoles (560.215) a aquellas tierras, siendo el retorno muy inferior (162.297 españoles), lo que determinó una pérdida demográfica neta para España cercana a los cuatrocientos mil habitantes (397.918). El mayor índice de permanencia de la emigración española en Latinoamérica con respecto al período anterior a la guerra civil ( $71 \%$ ahora, frente al $36 \%$ de entonces) puede tener varias explicaciones: por un lado, el proceso de selección al que se vió sometida, pues éste aseguraba mayores posibilidades de éxito al responder la emigración española casi en su mayoría a la demanda latinoamericana; por otro, la desaparición de la corriente emigratoria estacional tanto a Cuba como a Argentina, que tanta importancia tuvo en las tres primeras décadas del siglo; y, por último, la escasa duración del período analizado, que impide comprobar cual fue el grado de retorno de esos emigrantes españoles cuando la situación económica empeore en América Latina a partir de 1960.

\footnotetext{
${ }^{17}$ PALAZÓN, op. cit., pp. 130-133.
} 


\section{CUADRO III \\ Evolución anual del movimiento migratorio español a Latinoamerica \\ (1946-1958)}

\begin{tabular}{||r|r|r|r|}
\hline ANO & EMIGRACION & RETORNO & SALDO \\
\hline 1946 & 4.981 & 3.472 & -1.509 \\
1947 & 12.231 & 4.148 & -8.083 \\
1948 & 17.980 & 4.492 & -13.488 \\
1949 & 41.443 & 5.154 & -36.289 \\
1950 & 55.179 & 6,681 & -48.498 \\
1951 & 5.760 & 9.226 & -47.534 \\
1953 & 56.469 & 13.616 & -42.853 \\
1954 & 4.405 & 16.496 & -27.909 \\
1955 & 52.173 & 16.320 & -35.853 \\
1956 & 61.975 & 17.203 & -44.772 \\
1957 & 52.785 & 17.708 & -35.077 \\
1958 & 57.593 & 21.622 & -35.971 \\
\hline
\end{tabular}

Fuente: E.E., 1946-1951; E.M.M.T., 1952-1956; E.R.B., 1951-1956; E.MR.B., 1957; E.E.R.R.B., 1958. Elaboración propia.

La emigración española a Latinoamérica, a excepción de los tres primeros años en que el movimiento emigratorio aún padecía las restricciones del régimen franquista, superó los 40.000 emigrantes anuales. El retorno, por su parte, no superó los 20.000 españoles anuales, a excepción de los dos últimos años de esta etapa cuando los efectos de la crisis económica comenzaban a dejarse sentir en América Latina. La combinación de ambos fenómenos derivó en saldos migratorios netos anuales desfavorables para España superiores a los 20.000 efectivos (exceptuando los tres primeros años del período debido a los bajísimos volúmenes emigratorios).

Los principales destinos del movimiento emigratorio español en este período son Argentina y Venezuela, con un total de 398.759 emigrantes, de tal forma que la primera absorbe al $40 \%$ de la corriente emigratoria a Latinoamérica y la segunda al $31 \%$. En el caso argentino se repite la primacía como destino del período anterior a la guerra civil, mientras que Venezuela, que era un destino periférico entonces, pasa a ser un destino prioritario ahora debido al crecimiento económico espectacular que experimenta como consecuencia de la exportación de hidrocarburos.

Las causas de la atracción argentina debemos atribuirlas, por un lado, a la cadena migratoria (no hay que olvidar que en este país reside el mayor número de españoles de toda Latinoamérica, aproximadamente 750.000 en el año 1950), y, por otro, al auge económico que experimenta Argentina en estos años. La prosperidad económica argentina basada en el aumento de las exportaciones agropecuarias durante la década de los cuarenta y primeros años cincuenta, permitió al Gobierno peronista, gracias a las divisas obtenidas, acentuar su control sobre la economía, nacionalizar importantes servicios (ferrocarriles, teléfonos, gas y transporte urbano) e invertir en la expansión de la industria ligera. De esa forma, el país alcanzó el pleno empleo, 
y el éxodo rural podía ser absorbido por una industria en desarrollo ${ }^{18}$.

\section{CUADRO IV}

Distribución por países del movimiento migratorio español a Latinoamérica (1946-1958)

\begin{tabular}{|c|c|c|c|c|}
\hline PAISES & EMIGRACION & TOTAL \% & RETORNO & TOTAL $\%$ \\
\hline $\begin{array}{l}\text { Argentina } \\
\text { Bolivia } \\
\text { Brasil } \\
\text { Colombia } \\
\text { Costa Rica } \\
\text { Cuba } \\
\text { Chile } \\
\text { Ecuador } \\
\text { Guatemala } \\
\text { Honduras } \\
\text { México } \\
\text { Nicaragua } \\
\text { Panama } \\
\text { Paraguay } \\
\text { Perú } \\
\text { Puerto Rico } \\
\text { R. Dominicana } \\
\text { Ei Salvador } \\
\text { Uruguay } \\
\text { Venezuela } \\
\text { América latina }\end{array}$ & $\begin{array}{r}224.897 \\
0 \\
84.590 \\
4.252 \\
72 \\
19.871 \\
1.298 \\
448 \\
14 \\
0 \\
5.304 \\
0 \\
989 \\
380 \\
1.530 \\
328 \\
5.800 \\
57 \\
37.043 \\
173.862 \\
560.215\end{array}$ & $\begin{array}{c}40,14 \\
0 \\
15,10 \\
0,76 \\
0,01 \\
3,55 \\
0,23 \\
0,08 \\
0 \\
0 \\
0,95 \\
0,18 \\
0,18 \\
0,07 \\
0,27 \\
0,06 \\
1,04 \\
0,01 \\
6,61 \\
31,03 \\
100\end{array}$ & $\begin{array}{r}57.040 \\
6 \\
17.726 \\
1.340 \\
6 \\
13.588 \\
1.304 \\
222 \\
5 \\
1 \\
3.027 \\
6 \\
768 \\
0 \\
884 \\
133 \\
3.144 \\
99 \\
9.895 \\
53.102 \\
162.297\end{array}$ & $\begin{array}{c}35,14 \\
0 \\
10,92 \\
0,82 \\
0 \\
8,37 \\
0,8 \\
0,14 \\
0 \\
0 \\
1,86 \\
0 \\
0,47 \\
0 \\
0,54 \\
0,08 \\
1,94 \\
0,06 \\
6,09 \\
32,71 \\
100\end{array}$ \\
\hline
\end{tabular}

Fuente: E.E., 1946-1951; E.M.M.T., 1952-1956; E.R.B., 1951-1956; E.M.R.B., 1957; E.ERR.B., 1958. Elaboración propia.

El nuevo panorama económico argentino determinó la necesidad de atraer obreros para la industria, técnicos especializados para la dirección de empresas y la realización de las obras de infraestructura necesarias, así como colonos agrícolas destinados a poblar las zonas menos habitadas del país o aquellas donde el éxodo rural provocaba dificultades a la producción agrícola. Esta demanda ya aparece plasmada en el Convenio comercial hispano-argentino de 30 de octubre de 1946, por el que España se comprometía a no adoptar trabas o restricciones que entorpeciesen la emigración española, incluyendo los técnicos y obreros especializados, así como familias para colonizar nuevos espacios agrícolas ${ }^{19}$.

El Primer Plan Quinquenal peronista (1948-1952) puso de manifiesto una política selectiva en matería de inmigración, de tal forma que sólo se permitiría la entrada en el país de todo aquel que fuera reclamado por un pariente, así como a los obreros industriales, técnicos especializados y agricultores, estuviesen o no reclamados por empresas nacionales ${ }^{20}$. Sin embargo, y para evitar una congestión del mercado

${ }^{18}$ HALPERIN DONGHI, T.: Historia Contemporánea de América Latina, Madrid, Alianza Editorial. 1977, pp. 392-393.

19 Archivo del Ministerio de Asuntos Exteriores (A.M.A.E.), Leg. 1731, Exp. 2.

${ }^{20}$ MARTI BUFILL, op. cit., p. 198. 
laboral, las entradas quedaban limitadas a un máximo de 50.000 individuos por año ${ }^{21}$. En este sentido, se firma en Madrid, en 1948, el Convenio hispano-argentino de Emigración, que preveía la emigración por carta de llamada, contrato de trabajo, e incluso el reclutamiento de colonos por parte de las autoridades argentinas ${ }^{22}$.

Parte del aumento que experimentan las cifras de emigrantes españoles a Argentina desde 1948 debemos entenderlo como una consecuencia de la firma de este acuerdo. Sin embargo, el esplendor económico argentino pronto entraría en crisis. Tres son las causas que explican este declive, cuyo resultado fue un déficit de la balanza de pagos, la devaluación del peso y un progresivo aumento del coste de la vida a partir del año $1952^{23}: 1^{9}$ ) la caída de las exportaciones derivada de la reconstrucción europea, al prescindir los países europeos de Argentina como proveedora; $2^{\circ}$ ) el fracaso del proyecto de industrialización peronista basado en una industria ligera, al no haberse potenciado al mismo tiempo una industria pesada que lo respaldase; y $3^{\circ}$ ) la disminución de la superficie cultivada como consecuencia de los bajos precios agrícolas ofrecidos por el Gobierno, monopolizador de las compras.

Junto a ese empeoramiento de la situación económica, otros dos factores nos sirven para entender el descenso que experimenta la emigración española a Argentina a partir de 1953: por una parte, el desvío de la corriente hacia Venezuela, que intensifica por entonces su demanda de fuerza de trabajo inmigrante, y que parece ofrecer excelentes perspectivas al emigrante español, 0 , al menos, mucho mejores que Argentina; y, por otra, la puesta en marcha del Segundo Plan Quinquenal peronista (1953-1957), que determinó un aumento del control y orientación de los contingentes inmigratorios, restringiéndose al máximo la inmigración hacia Buenos Aires y orientándola hacia el medio rural o hacia las ciudades de Rosario y Bahía Blanca ${ }^{24}$.

En el caso venezolano es el rápido crecimiento económico el que explica su atractivo para la emigración extranjera. Este despegue económico se fundamentó en el incremento de la producción de petróleo, gracias al aumento de la demanda exterior. Dicho incremento, no sólo permitió que crecieran los recursos fiscales en manos del Estado, sino que conllevó también un aumento de las inversiones en la industria petrolera y en la construcción de nuevas refinerías (el tratamiento del crudo se hacía en el país), al mismo tiempo que estimuló la expansión industrial y de la construcción $^{25}$. Entre 1946 y 1948, el Gobierno de Acción Democrática fue partidario de la inmigración como elemento de progreso, siempre y cuando los inmigrantes no compitieran con los venezolanos por los mismos empleos, y no tuvieran problemas de asimilación social. Así pues, se enviaron a las misiones diplomáticas en el extranjero, listas de las actividades necesitadas de fuerza de trabajo. Además, se otorgó preferencia a los inmigrantes españoles por compartir

${ }^{21}$ A.M.A.E., Leg. 1731, Exp. 2.

${ }^{22}$ MARTI BUFILL, op. cit., p. 205.

${ }^{23}$ GARCIA FERNANDEZ, op. cit., p. 258.

24 Esta nueva orientación de la política migratoria argentina aparece plasmada ya en el Reglamento de Inmigración de 22 de febrero de 1952 (MARTI BUFILL, op. cit., pp. 199-203).

${ }^{25}$ PELLEGRINO, A.: La inmigración en Venezuela en el siglo XX, Caracas, inédito, 1985, p. 79. 
tradiciones culturales, lengua y religión con los venezolanos, y su fácil asimilación. Sin embargo, el número de emigrantes llegados oficialmente desde territorio español a Venezuela entre 1946 y 1948 es muy bajo, ya que la ruptura de relaciones diplomáticas entre Venezuela y España hizo que el Gobierno venezolano optase por privilegiar a los refugiados españoles ${ }^{26}$, así como a los canarios que emigraban clandestinamente del Archipielago ${ }^{27}$.

Entre 1949 y 1952, la junta militar que toma el poder apenas presta atención a la inmigración, y eso permite entender que la emigración española no supere los 11.000 efectivos anuales. Por otra parte, el restablecimiento de relaciones con España determinó que el Gobierno venezolano prohibiese la entrada de todo canario o español que llegase de forma clandestina ${ }^{28}$. Con la llegada al poder de Marcos Pérez Jiménez en 1953, se impulsa nuevamente una política favorable a la inmigración, basada en la mejora sustancial que experimentarían las condiciones económicas y sociales al enriquecerse la población venezolana con el aporte de los extranjeros ${ }^{29}$. En 1954, el Ministerio del Interior y la Dirección de Identificación y Extranjería emite una circular en la que se indican los requisitos que deben cumplir los inmigrantes para ser admitidos en el país: a) ser menores de 35 años; b) alfabetos; c) poseer certificados de buena salud y buena conducta; y d) no estar incluídos dentro de las restricciones de la Ley de Inmigración de 1936. Esta circular limitaba, además, la inmigración a los emigrantes procedentes de España, Italia y Portugal, quedando los Consulados de Venezuela en cada uno de esos países encargados de realizar las tareas de propaganda y recluta. Un año después, otra circular ampliaba el ámbito de procedencia de los inmigrantes al resto de países europeos, al Líbano, a los Estados Unidos de Norteamérica y a Canada ${ }^{30}$.

El empeoramiento de la situación económica del país y el creciente desempleo determinaron que unos meses después de la caída de Pérez Jiménez en enero de 1958, Venezuela cerrase temporalmente sus puertas a la inmigración extranjera, a

${ }^{26}$ BERGLUND, S.: "... Y los últimos serán los primeros. La inmigración masiva en Venezuela, 1945-1961", en Sánchez-Albornoz, N., Población y mano de obra en América Latina, Madrid, Alianza Editorial, 1985, p. 316.

27 Los emigrantes clandestinos canarios utilizarían pequeños barcos para evitar el control de la policía y como único medio de transporte factible ante la imposibilidad de costearse el pasaje en las líneas regulares de navegación (GONZÁLEZ-ROTHVOSS Y GIL, M., 1958: "La emigración a América, a Europa y al resto del mundo", en Semanas Sociales de España, Los problemas de la migración española, Vigo-Santiago, 1958, p. 26).

${ }^{28}$ Sobre la emigración clandestina canaria a Venezuela y la actitud hacia ella del Gobieno venezolano durante el año 1950 pueden consultarse en el A.M.A.E. los expedientes 5 al 12 y 27 al 30 del Legajo R-5671.

29 Véase BERGLUND, op. cit., p. 317. Tampoco debemos olvidar que esa política respondía a la doctrina del nuevo gobiemo conocida como "El Nuevo Ideal Nacional", y no hacía sino copiar, en materia de inmigración, las líneas seguidas por los gobiemos de Argentina, Brasil, Cuba, Chile, etc., en el último tercio del siglo XIX y principios del siglo XX, en el sentido de entender al inmigrante como un elemento de progreso que permite al país obtener mano de obra cualificada y dispuesta a ser utilizada sin apenas coste alguno adicional.

${ }^{30}$ PELLEGRINO, op. cit., p. 77. 
excepción de los familiares directos de los inmigrantes ya establecidos en tierras venezolanas $^{31}$. Estas restricciones explican el descenso de la emigración española en 1958 con respecto a años anteriores, a la vez que las dificultades por las que atravesaba el país sirven para entender el aumento del retorno, ya que hasta 1957 las cifras de españoles que regresaban de Venezuela no superaban los 10.000 retornados anuales.

La importancia de la corriente migratoria española a Venezuela determinó un fortísimo aumento de la colonia española asentada en este país, de hecho los 6.959 españoles censados allí en 1941 se multiplicaron por veinticuatro en tan sólo veinte años, al contabilizarse 166.660 españoles en el año 1961.

Como destinos secundarios de la emigración española aparecen Brasil y Uruguay, que reciben durante este período más de 35.000 emigrantes españoles cada uno; de hecho, hacia el primero se dirige el $15 \%$ de la corriente emigratoria española, y hacia el segundo el 7\%. Estos dos países eran también destinos secundarios en el período anterior a la guerra civil, y el mantenimiento de esta situación se explica, tanto por la cadena migratoria, como por la atracción que para el emigrante español ofrecían gracias al florecimiento económico que presentan tras la Segunda Guerra Mundial.

Al igual que ocurre en Argentina y Venezuela, la emigración española es atraída a Brasil a causa de su período de esplendor económico entre los años 1945 y 1955. El despegue económico de Brasil se asentó en los buenos precios internacionales del café, pues éstos permitieron una acumulación de capital que se invirtió en la consolidación del proceso de industrialización comenzado en la década de los treinta con vistas a sustituir importaciones. Este proceso se basaría en la expansión de la industria ligera ${ }^{32}$, de ahí que la demanda del mercado laboral brasileño exigiese una inmigración extranjera de personal cualificado (obreros industriales y técnicos, sobre todo), aunque tampoco pondría trabas a la llegada de agricultores con los que colonizar el interior ${ }^{33}$.

Ahora bien, hay que tener en cuenta que la existencia en Brasil de una numerosa mano de obra poco cualificada, tanto en el campo como en las ciudades, impedía la llegada de unos flujos inmigratorios procedentes del exterior en cuantías similares a las de principios de siglo. Por tanto, el incremento de la emigración española se basó en las buenas perspectivas que para el inmigrante cualificado ofrecía el país entre 1950 y $1955^{34}$, así como que fuese en estos años, cuando los saldos migratorios netos anuales son más desfavorables a España. Sin embargo, el hecho de que Brasil no afianzase su proceso de industrialización con un desarrollo paralelo de la industria pesada, suponía que el país debía seguir dependiendo de las importaciones para la obtención de metales y combustibles. Por eso, cuando los precios mundiales del café sufrieron una caída a finales de los años cincuenta, por la concurrencia del café

\footnotetext{
${ }^{31}$ BERGLUND, op. cit, p. 317.

${ }^{32}$ HALPERIN, op. cit.. p. 385.

${ }^{33}$ GONZALEZ-ROTHVOSS, op. cit., 10.

34 Tampoco debe descartarse la posible repercusión de la cadena migratoria, pues, no hay que olvidar que en Brasil residían, en 1940, cerca de 160.000 españoles.
} 
africano, la economía brasileña entró en crisis, y el Gobierno no pudo evitar, a pesar de tener el país una de las tasas de crecimiento del P.I.B. más altas del mundo, que los desequilibrios en la balanza comercial incidieran negativamente provocando una inflación violenta, que al no ir acompañada de aumentos salariales, hizo perder poder adquisitivo a los sectores populares ${ }^{35}$.

Esta crisis, y la pérdida de oportunidades para el inmigrante, determinaron el descenso de la emigración española a partir de 1956 y un ligero aumento del retorno, hechos estos que no impidieron que los saldos migratorios anuales continuaran siendo desfavorables para España.

Uruguay también conoció una etapa de prosperidad económica tras la Segunda Guerra Mundial, que duraría hasta mediados de la década de los cincuenta. Esta prosperidad, basada en la acumulación de capitales que podían ser invertidos en el país, procedía, por una parte, del aumento de las exportaciones pecuarias gracias a los buenos precios internacionales de la lana, $\mathrm{y}$, por otra, de la llegada al país de capitales fugados de Europa durante la Guerra de Corea ${ }^{36}$. Como sucedió en Argentina y Brasil, Uruguay destinó la mayor parte de las inversiones a afianzar su proceso de industrialización, pero, como aquéllos, cometió el error de potenciar una industria ligera sin desarrollar, por igual, una industria pesada que abasteciese a la anterior de materias primas semielaboradas o de combustibles, evitando así las importaciones de estos productos.

La industrialización del país permitió al sector una fuerte absorción de mano de obra y un aumento de la demanda de fuerza de trabajo inmigrante especializada, tanto para la industria, como para la construcción; a su vez, el fuerte éxodo rural al amenazar la producción agraria determinó que el Gobierno también optase por atraer obreros agrícolas y pecuario ${ }^{37}$.

Este contexto económico favorable a la absorción de inmigrantes y las perspectivas de progreso que ofrecía Uruguay al emigrante explican el aumento de la emigración española a este país en la década de los cincuenta; no obstante, la llegada de españoles no alcanza las cifras de Argentina, Venezuela y Brasil, porque Uruguay tiene menos capacidad de absorción y porque aquéllos presentan mayor atractivo para la corriente emigratoria española. De todas formas, la emigración española a Uruguay supera todos los años al retorno, lo que implica saldos migratorios netos anuales desfavorables a España.

Los demás países latinoamericanos pueden ser considerados como destinos periféricos del movimiento emigratorio español, pues en ningún caso se superan los 20.000 emigrantes al final de la etapa analizada. Aún así, entre estos países pueden destacarse Cuba, la República Dominicana y México, que reciben más de 5.000 emigrantes españoles cada uno de ellos. La pérdida de importancia como destinos de

\footnotetext{
${ }^{35}$ HALPERIN, op. cit., pp. 384-386.

${ }^{36}$ HALPERIN, op. cit., p. 414.

${ }^{37}$ Así quedaba establecido en el Reglamento sobre Entrada y Permanencia de Extranjeros de 28 de febrero de 1947 (GONZÁLEZ-ROTHVOSS Y GIL, M., "La emigración española a Iberoamérica" en Estudios Demograficos, vol. III, 1949, p. 32).
} 
Cuba, México o Chile con respecto al período anterior a la guerra civil, podría ser explicada en función de la presencia de una fuerza de trabajo local con capacidad para cubrir la demanda, de un crecimiento económico menor, o de peores expectativas de éxito para el emigrante frente a otros destinos.

\subsubsection{Características del movimimiento migratorio español a Latinoamérica en este periodo}

Como consecuencia de la demanda latinoamericana, el movimiento emigratorio español se caracterizaría por:

a) Individuos en edad de acceder al mercado laboral. Los emigrantes entre 15 y 55 años de edad suponen más de las tres cuartas partes del total anual durante todo el período.

b) Primacía de los emigrantes varones. Sin embargo, la sex ratio queda muy por debajo de la que presenta la emigración anterior a la guerra civil (138 frente a 254), hecho explicable por la desaparición de la emigración estacional (puramente masculina) y por la mayor emigración femenina, sobre todo, para llevar a cabo la reagrupación familiar.

c) Una elevada tasa de actividad. La mitad de los emigrantes declara una profesión al embarcar. Esta tasa no es mayor debido, seguramente, al aumento de la presencia femenina en el flujo emigratorio, puesto que muchas de estas mujeres, así como los menores de 15 años, aparecen clasificados por las autoridades como emigrantes sin profesión, aunque luego sí desempeñen algún empleo al llegar a América.

d) Predominio de dos sectores de actividad: la industria y la agricultura. El $41 \%$ de los emigrantes españoles que declaran una profesión dicen ser obreros industriales y el $40 \%$ agricultores. Los evidentes cambios que ofrece este reparto frente al que presentaba el período anterior a la guerra civil, cuando los agricultores suponían las dos terceras partes de los activos y los obreros industriales y artesanos tan sólo un $10 \%$, se explican por:

1) La fuerte demanda de obreros industriales que realizan los países latinoamericanos para afianzar sus procesos de industrialización.

2) El descenso de la emigración agrícola hacia América Latina, ya que, si bien los campesinos españoles constituían la mano de obra más propensa a la emigración, sin embargo, por un lado, no querían emigrar a América para seguir siendo agricultores (en muchos casos como colonos agrícolas), y, por otro, debido a su escasa cualificación ya no encontraban en las ciudades las mismas posibilidades que a principios de siglo, pues, las ocupaciones urbanas que desempeñaban entonces, eran ahora acaparadas por el intenso éxodo rural interior ${ }^{38}$.

A partir de 1959 la situación de crisis se agudizará en América Latina y aunque el gobierno español impulsará desde entonces todavía más la emigración exterior para paliar los efectos de la puesta en marcha del Plan de Estabilización de 1959, dar

${ }^{38}$ GARCIA FERNANDEZ, op. cit., pp. 50-51. 
salida al fuerte éxodo rural y obtener divisas, la dirección tomada por los emigrantes españoles supondrá un cambio radical con respecto a lo tradicional, al ser en estos momentos Europa Occidental (Alemania, Francia, Suiza, Gran Bretaña, Bélgica, etc.) quien atraiga al grueso de la emigración española, no sólo por ser un destino mucho más cercano, sino también por ofrecer mayores garantías de éxito que una Latinoamérica en proceso de recesión económica. 